\title{
MICROEMULSION: A NEW-TYPE OF FORMULATION DEDICATED TO SKIN ANTI-AGING PRODUCTS
}

Anissa Azouaoui', Christian Tran', Audrey Gueniche',

Gabrielle Sore ${ }^{2}$, Guillaume Cassin ${ }^{2}$,

Julien Laboureau', Chantal Jouy ${ }^{2}$

L'oréal Research \& Innovation, ${ }^{1}$ Aulnay-sous-Bois, ${ }^{2}$ Chevilly-Larue, France.

\section{OBJECTIVES}

The microemulsions based on polyglyceryl surfactants are able to boost the in vivo efficacy of active cosmetic ingredients by favoring excellent transdermal delivery of almost all skin care actives, with no compromise on skin tolerance, formula stability, and offering a pleasant texture.

We investigate if, per se, these microemulsions are able to exert anti-aging benefits.

To explore the efficacy of these new formulae, two clinical studies were carried out.

\section{METHODS}

Study 1 : Global anti-aging clinical study
Thirty eight caucasian women from 43 to 65 years old with moderate crow's feet and

Thirty eight caucasian women from 43 to 65 years old with moderate crow's feet and
under eye wrinkles were recruited. The volunteers applied the microemulsion without any active ingredient on their whole face once daily for 6 months.

Study 2 : Firmness focused clinical study

Seventy nine Caucasian women from 55 to 65 years old with a lack of skin firmness were randomly assigned to either the test product group ( $n=39$ ) or a classical skin care emulsion group ( $n=40$ ). The volunteers applied their assigned product on the whole face twice daily for 3 months.

Efficacy assessments for both studies

Study 1: Crow's feet (grade 0-6) and under eye (grade 0-5) wrinkles were assessed by clinical scoring, and skin firmness measured by Cutometer on cheekbones at D0, D7, D14, D28, D56, D84 and D168. Study 2: Skin firmness was assessed by Cutometer and Dermal Torque Meter on cheekbones at D0, D28 and D56 and D84

\section{RESULTS}

In study 1 , the microemulsion shows a significant improvement of crow's feet wrinkles and under eye wrinkles at all times from D28 versus baseline.

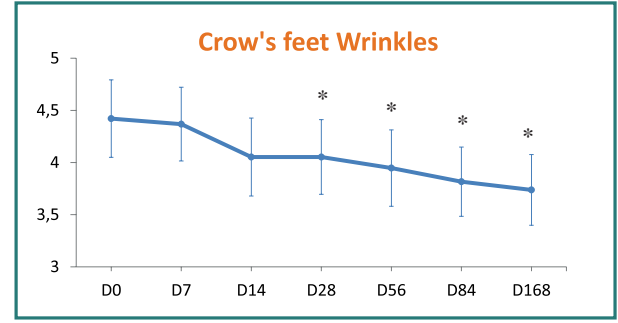

Figure 1: Crow's feet wrinkles grade

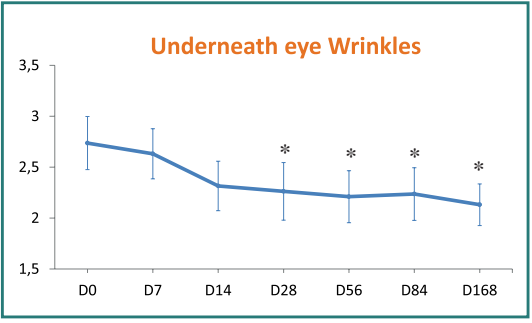

Flgure 2: Under eye wrinkles grade

The microemulsion significantly improved pure elasticity (Ur/Ue) over time from D56 compare to baseline.

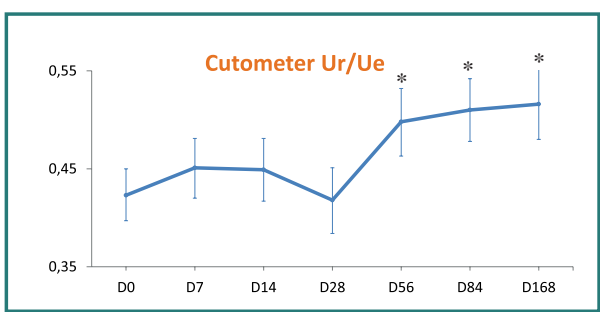

Flgure 3: Pure elasticity Ur/Ue by Cutometer

In study 2 , the microemulsion significantly improved pure elasticity (Ur/Ue) over time from D28 compare to baseline. Furtermore, the improvement in the microemulsion group at D84 is significantly greater than that in the classical skin care emulsion group

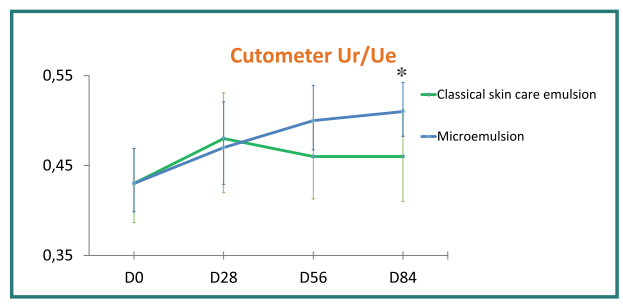

Flgure 4: Pure elasticity Ur/Ue by Cutometer

\section{CONCLUSION}

The results of these studies demonstrate that this specific and well tolerated formula brings per se beneficial effects against skin aging. Indeed, the findings suggest that this type of microemulsion based on polyglyceryl surfactants could correct some facial signs considered as hallmarks of skin aging appearance such as wrinkles and skin firmness.

These results bring us the opportunity to use this kind of formula to raise the level of performance of active ingredients. 